\title{
LIVROS RECEBIDOS
}

\author{
EDITORA HUCITEC - co-edição com a ABRASCO \\ Rua Gil Eanes, 713 - 04601-042 - São Paulo - S.P. \\ Telefones (011) 530-9208 e 543-0653
}

MENDES, Eugênio Vilaça (org.) Distrito Sanitário. O processo social de mudança das práticas sanitárias do Sistema Único de Saúde. 1993, 310p.

A obra reune textos que colocam em discussão o Distrito Sanaitário, enquanto elemento essencial de construção de um sistema de saúde que signifique a real transformação das práticas assistenciais. Nesse sentido, apresenta aspectos teórico-conceituais, que vão desde aas políticas de saúde nos anos 80, passando pela concepção de Distrito Sanitário enquanto processo social, até a metodologia do planejamento e programação situacional e dos sistemas de informação para Distritos Sanitários. Os textos são escritos por Carmen Fontes, Carmen Vieira Unglert, Cláudio Grego, Eliane Araújo, Eugênio Vilaça Mendes, Francisco Notarbartolo de Villarosa, Jaimilson Silva Paim, Maria Rosa Logiodice Cardoso e Renato Tasca.

VAUGHAN, J.P. e MORROW, R. A. Epidemiologia para os Municipios. Manual para gerenciamento dos distritos sanitários. São Paulo, 1993. Tradução de Carlos Dora, Iná dos Santos Hallal e César Gomes Victora.

O livro pretende ser um guia prático sobre epidemiologia e sua relação com o planejamento, gerenciamento e avaliação, dirigido às pessoas que têm como responsabilidade a implementação dos cuidados básicos de saúde. Apresenta aspectos epidemiológicos e populacionais do sistema de informação e vigilância epidemiológica, organização de investigação e estudos epidemiológicos, divulgação de dados e planejamento de saúde nos Distritos Sanitários. É de extrema atualidade na medida em que se discute a organização de modelos assistenciais de base epidemiológica.

\section{FUNDAÇÃO OSVALDO CRUZ - ESCOLA NACIONAL DE SAÚDE PÚBLICA TEXTOS DE APOIO}

Secretaria de Desenvolvimento Educacional

Rua Leopoldo Bulhões, 1480 - Manguinhos

CEP: 21.041-210 Rio de Janeiro - RJ

Telefone: (021) 590.3789 - ramais 2010 e 2011

GIOVANELLA, Ligia (Org.) Planejamento estratégico, programação e orçamentação em saúde. Rio de Janeiro, 1993, 80p.

O texto escrito por vários autores, apresenta um histórico đó piarıjejarriento de saúde na América Latina, as 3 vertentes do enfoque estratégico-situacional, as relações entre planejamento e programação e aspectos da orçamentação em saúde. Entre os autores estão Denise Nabuco Villa Forte, Lígia Giovanella, Maria Helena Machado, Marilene de Castilho Sá, Maura Taveira, Sílvia Marta Porto, Soraya Almeida Belisário e Vera Lúcia Almeida Formigli. 